\title{
STRATEGI PENINGKATAN MUTU KECAP ASIN BERBASIS HARAPAN PELANGGAN (Studi Kasus Perusahaan Kecap Asin Cap Ikan Suramas, Kecamatan Kaliwates, Kabupaten Jember)
}

\author{
M. Fatoni Kurnianto1, Soetriono², Bagus Putu Y Kurniawan ${ }^{3}$ \\ ${ }^{1}$ Mahasiswa Program Studi Agribisnis Program Pasca Sarjana Fakultas Pertanian Universitas \\ Jember ${ }^{2}$ Jurusan Agribisnis Fakultas Pertanian Universitas Jember \\ ${ }^{3}$ Jurusan Manajemen Agribisnis, Politeknik Negeri Jember \\ E-mail: ftnpolije@gmail.com
}

\begin{abstract}
ABSTRAK
Kecap asin merupakan industri makanan yang mempunyai perkembangan yang cukup pesat. Meningkatnya jumlah penduduk dan tingkat konsumsi kecap menyebabkan pasar kecap asin menjadi sangat prospektif .Hal ini menjadi daya tarik kuat bagi perusahaan besar untuk merambah kedalam bisnis pengolahan kecap asin.Persaingan usaha yang sangat ketat menyebabkan perusahaan kecap asin skala kecil kehilangan pasarnya karena mutu produk nya kalah bersaing dengan produk dari perusahaan besar. Jika dibiarkan, keadaan ini dapat berakibat pada hilangnya daya saing perusahaan kecap asin skala kecil.Penelitian ini bertujuan untuk merumuskan strategi peningkatan mutuk ecap asin berbasis harapan pelanggan pada perusahaan skala kecil.Penelitian dilakukan secara studi kasus di perusahaan kecapasin cap IkanSuramas di Kabupaten Jember. Metode yang digunakan adalah Quality Function Deployment (QFD) untuk menentukan prioritas persyaratan pelanggan dan persyaratan teknis, dan fuzzy Analytical Hierarchy Process (AHP) untuk merumuskan strategi peningkatan mutu produk kecap asin.Hasil penelitian menunjukkan bahwapersyaratan teknis yang menjadi prioritas untuk diperbaiki dalam rangka meningkatkan kinerja prioritas atribut mutu yang mampu memuaskan harapan pelanggan adalah 1) proses pengemasan; 2) proses distribusi dan pemasaran produk; 3) proses fermentasi; 4) proses penambahan bahan pengawet; 5) proses pemasakan dengan penambahan gula dan bumbu; dan 6) proses pengendapan dan penyaringan. Alternatif strategi peningkatan mutu kecap asin yang efektif adalah strategi Gugus Kendal iMutu (GKM).
\end{abstract}

Kata kunci $\quad$ : $\quad$ Kecap asin, mutu, kepuasanpelanggan, QFD, AHP, fuzzy, GKM 
Keywords : Salty ketchup, quality, customer expectation, QFD, AHP, fuzzy, QCC

\section{PENDAHULUAN}

Memasuki abad ke-21, agroindustri pangan menghadapi fenomena global yang semakin menguat. Munculnya globalisasi perekonomian tidak hanya ditandai dengan tingkat persaingan usaha yang semakin ketat saja, namun juga muncul tuntutan pelanggan yang semakin tinggi terhadap mutu produk, terutama dalam hal persyaratan mutu produk (fitur), distribusi, pelayanan, harga dan jaminan keamanan pangan (Ali et al, 2010). Arus globalisasi yang melanda agroindustri pangan semakin tidak terbendung seiring dengan meluasnya liberalisasi perdagangan diberbagai negara, terjadinya kemajuan teknologi dan informasi, serta perubahan perilaku dan budaya pelanggan akibat meningkatnya tingkat pendidikan masyarakat. Situasi tersebut telah mendorong produsen agroindustri pangan untuk dapat menghasilkan produk yang berdaya saing tinggi dalam usaha memenangkan pangsa pasar (Passemard dan Kleiner, 2000; Josling, 1999).

Menurut Magutu et al (2010)mutu produk merupakan faktor kunci dalam meningkatkan daya saing perusahaan di era global. UNIDO (2006) secara singkat menyatakan bahwa produk bermutu adalah produk yang mampu memenuhi kebutuhan dan harapan pelanggan. Konsep tersebut menegaskan bahwa upaya perbaikan mutu produk tidak cukup dilakukan dengan meningkatkan keunggulan produk secara kompetitif saja tanpa memperhatikan harapan pelanggan.

Agroindustri kecap adalah salah satu kelompok industri makanan yang mengalami dampak globalisasi. Jumlah industri kecap cenderung meningkat setiap tahun yang disebabkan karena meningkatnya jumlah penduduk dan berkembangnya industri yang memanfaatkan produk kecap, seperti industri mie instan, makanan ringan (snack), warung dan rumah makan (restaurant) (SWA, 2013).

Menurut Chan dan $\mathrm{Wu}$ (2002) peningkatan mutu produk, termasuk kecap, dapat dilakukan dengan mengetahui karakteristik produk yang diharapkan pelanggan kemudian menerjemahkan harapan tersebut sebagai dasar dalam merancang dan mengembangkan proses produksi sehingga dapat menghasilkan mutu yang sesuai. Metode QFD (quality 
function deployment) merupakan metode yang telah digunakan secara luas untuk mengetahui prioritas harapan pelanggan terhadap suatu produk sekaligus menghubungkannya dengan kebutuhan proses dan prioritas pengembangannya terhadap pemenuhan harapan tersebut. QFD merupakan alat manajemen kualitas yang didasarkan atas pengenalan suara pelanggan (voice of costumers) untuk perbaikan produk secara sistematik dan komprehensif untuk menjamin bahwa produk yang dihasilkan telah memenuhi harapan pelanggan.

Penerapan QFD untuk meningkatkan mutu produk kecap asin pada industri kecil dan menengah sangat relevan karena kemampuan produk untuk memenuhi dan memuaskan harapan pelanggan merupakan kunci utama dalam meningkatkan daya saing dan memenangkan persaingan pasar. Walaupun QFD telah terbukti sebagai metode yang memiliki dampak positif bagi peningkatan kinerja mutu perusahaan, terutama dalam meningkatkan efisiensi waktu dan mengurangi biaya rekayasa proses (Marimin dan Muspitawati, 2002), namun menurut Kwong dan Bai (2002), efektifitas QFD masih dapat ditingkatkan dengan memperbaiki salah satu teknik dalam tahapan-tahapan QFD, yaitu tahap penentuan derajat kepentingan harapan pelanggan. Hal ini disebabkan harapan pelanggan sangat beragam dan seringkali bersifat kabur (vague), sehingga diperlukan pendekatan yang tepat untuk menanganinya. Teknik fuzzy dapat digunakan untuk menangani kelemahan ini karena teknik ini dikembangkan sebagai pengukuran beragam fenomena ambiguity secara matematis pada lingkungan yang tidak pasti dan tidak tepat (Marimin, 2005).

Agar hasil QFD dapat diimplementasikan secara tepat, maka diperlukan strategi yang tepat dan efektif. Strategi tersebut sangat diperlukan agar operasionalisasinya sesuai dengan sumberdaya yang dimiliki dan selaras dengan tujuan strategis perusahaan dalam rangka menghasilkan produk bermutu yang berdaya saing.Penentuan strategi merupakan permasalahan yang kompleks karena melibatkan berbagai komponen sumberdaya perusahaan yang saling berkaitan, seperti, biaya, fasilitas produksi, sumberdaya manusia (SDM), bahan baku dan manajemen. Kompleksitas permasalahan dan ketidakpastian dalam penentuan strategi juga memerlukan pendekatan yang tepat. Salah satu teknik yang dapat digunakan untuk menangani hal tersebut adalah fuzzy Proses Hirarki Analitik (FuzzyAnalitycal Hierarchi Process). Teknik ini telah dikenal mempunyai keunggulan dalam menguraikan permasalahan yang kompleks berdasarkan struktur hirarkinya dan memberikan prioritas bagi alternatif-alternatif secara menyeluruh dan terpadu (Ishizaka dan Labib, 2011). Penerapan logika fuzzy diyakini dapat mengurangi subyektifitas dan ketidaktepatan para pengambil keputusan yang mempunyai latar belakang disiplin keilmuan maupun sudut pandang yang beragam (Ayag dan Ozdemir, 2006).

Perusahaan kecap Hie Boen Pwee adalah salah satu produsen kecap asin di Kabupaten Jember yang menghasilkan produk kecap asin cap Ikan Suramas. Walaupun telah berdiri sejak 40 tahun lalu dan terus berkomitmen untuk menghasilkan produk bermutu, namun perusahaan ini ternyata belum mampu bersaing dengan produsen besar. Tujuan pelitian ini adalah secara umum adalah menentukan strategi untuk meningkatkan mutu produk kecap asin cap Ikan Suramas melalui penerapan metode QFD dan AHP menggunakan logika fuzzy. Secara khusus, penelitian ini mempunyai tujuan sebagai berikut: a) menentukan persyaratan mutu produk kecap asin cap Ikan Suramas berdasarkan harapan pelanggan; b) menilai kemampuan perusahaan dalam memenuhi harapan pelanggan; c) membandingkan kemampuan perusahaan dalam memenuhi persyaratan mutu kecap asin cap Ikan Suramas yang diharapkan pelanggan dengan perusahaan pesaingnya; d) menetapkan prioritas teknologi proses produksi yang dapat 
menghasilkan kecap asin cap Ikan Suramas sesuai harapan pelanggan; dan e) menetapkan strategi efektif dalam meningkatkan mutu produk kecap asin cap Ikan Suramas.

\section{METODOLOGI PENELITIAN}

\section{Metode Penelitian}

Penelitian ini terdiri dari 3 tahapan utama, meliputi: (i) studi pendahuluan; (ii) perencanaan mutu produk; (iii) penentuan strategi, seperti ditunjukkan pada Gambar 1. Studi pendahuluan dilakukan melalui pengkajian pustaka dan survey awal yang menghasilkaninformasi tentang permasalahan yang dihadapi oleh industri kecap di wilayah penelitian, harapan pelanggan terhadap mutu kecap asin yang beredar dan realitas pemenuhannya, dan teknik penyelesaian yang tepat dalam penyusunan strategi peningkatan mutu produk kecap.Tahapan perencanaan mutu produk bertujuan untuk menganalisis persyaratan mutu dan teknis dalam produksi kecap asin.Tahapan ini dilakukan dengan mengikuti tahapan dari metode QFD hingga dihasilkan matrik perencanaan HoQ (House of Quality). Tahap terakhir bertujuan untuk menetapkan stategi peningkatan mutu produk kecap yang tepat menggunakan teknik fuzzy AHP.

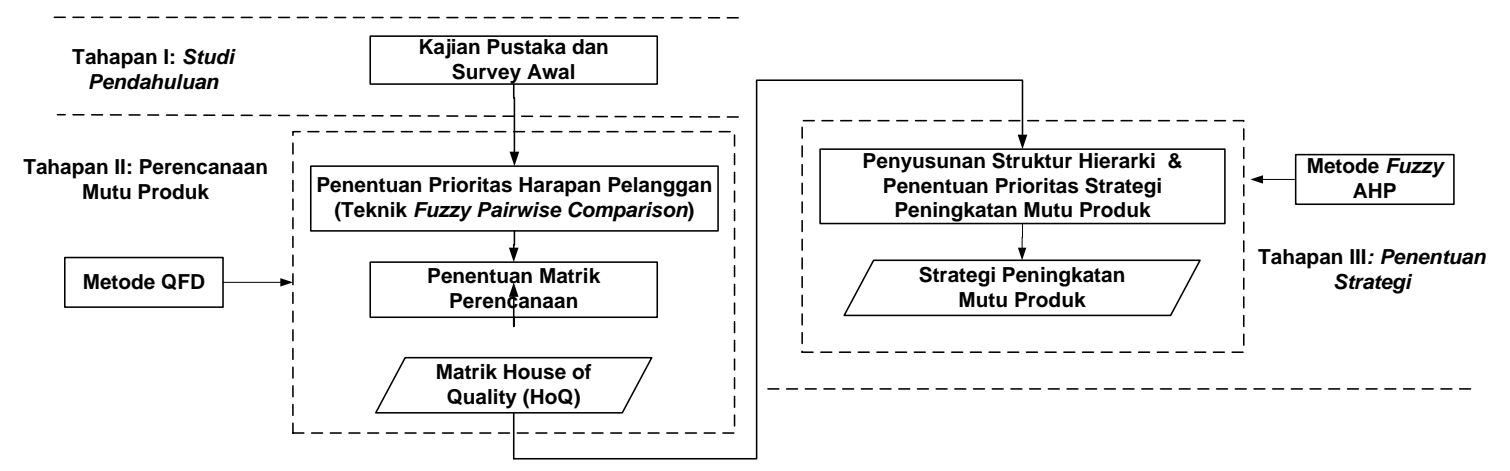

Gambar 1. Tahapan penelitian

\section{Metode Pengumpulan Data}

Data yang dikumpulkan pada penelitian ini terdiri dari data primer dan sekunder.Untuk analisis QFDdan fuzzy AHP digunakan data primer yang diperoleh melalui kuisioner maupun wawancara secara terstruktur(in-depth interview),expert survey dan brainstorming.Jumlah responden yang digunakan untuk keperluan analisis QFD adalah 100 orang pelanggan kecap asin cap Ikan Suramas yang berasal dari wilayah Kabupaten Jember yang dipilih menggunakan teknik sampel tanpa peluang (non probability sampling) dengan metode convenience sampling.Penentuan jumlah sampel menggunakan persamaan yang dikembangkan oleh Lemeshowdan David (1997). Sementara itu, responden ahli (pakar) untuk analisis fuzzy AHP berjumlah tiga orang yang dipilih secara sengaja yang berasal dari industri kecap asin, instansi pemerintahan terkait dan perguruan tinggi. Kriteria pemilihan pakaradalah berpendidikan atau berpengalaman dibidangnya, pejabat/praktisi yang menduduki jabatan strategis dan bersedia diwawancarai. 


\section{Teknik QFD}

Secara umum QFD dapat didefinisikan sebagaiproses perencanaandisain secara terstruktur yang mampu menjamin bahwa produk yang dihasilkandapat memenuhi kebutuhan dan harapan pelanggan (TsengdanTorng, 2011;Jaiswal, 2012; Lawdan Hua, 2007). Menurut GharakhanidanEslami(2012)dan Hamidullahet al. (2010) QFDterdiri dari tujuh tahapan yang diawali dengan mengidentifikasi suara atau persyaratan pelanggan, menganalisis persyaratan teknis proses kemudian menilai dan menganalisis hubunganhubungan yang terjadi pada keduanya menggunakan nilai skor hingga diperoleh matriks HoQ (Gambar 2).

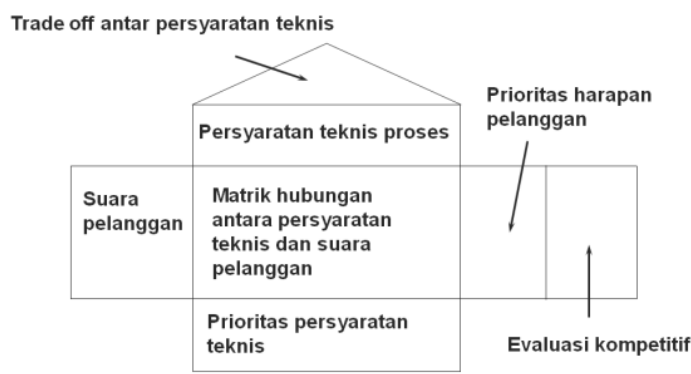

Gambar 1. Matrik perencanaan HoQ (house of quality)

1) Tahap identifikasi persyaratan pelanggan bertujuan untuk memperoleh informasi tentang atribut atau persyaratan mutu produksesuai harapan pelanggan. Pada tahap ini juga dilakukan penentuan bobot masing-masing atribut mutu kecap asin menggunakan teknik fuzzy pairwise comparison (Kwong dan Bai, 2002).

2) Tahap penentuan persyaratan teknisdilakukan untuk mempelajari, mengevaluasidan menetapkan ketentuan teknis dalam kaitannyadengan pemenuhan harapan pelanggan.

3) Pembentukan matrik hubungan antara keinginan pelanggan dengan ketentuan teknis dimaksudkan untuk mengidentifikasi intensitas hubungan antara harapan pelanggan dengan persyaratan teknis. Penilaian hubungan dilakukan menggunakan skor. Hasil yang diperoleh berupa matrik yang dapat menggambarkan intensitas hubungan yang terjadi, yaitukuat, sedang, lemah atau tidak ada hubungan.

4) Tahap trade offantar persyaratan teknisdilakukan untuk mengidentifikasi pola hubungan antar persyaratan teknis.Penilaian dilakukan menggunakan skor, kemudian hasilnya dituangkan dalam bentuk matrik hubungan (interrelationships) yang memberikan informasi persyaratan teknik mana saja yang saling mendukung atau bertentangan satu sama lain.

5) Tahap evaluasi kompetitif (benchmarking)dilakukandengan membandingkanmutu produk yang dihasilkan perusahaan dengan produk pesaing hingga diketahui keunggulan dan kelemahannya. Perbandingan dilakukan oleh responden ahli dengan menggunakan skala Likert lima jenjang $(1-5)$.

6) Tahap prioritas harapan pelanggan ditentukan berdasarkan tiga variabel penting, yaitu bobot persyaratan pelanggan,skala kenaikan,dan poin penjualan.Pada tahapan ini diperoleh nilai prioritas dari persyaratan pelanggan. Semakin tinggi nilai prioritasnya, maka semakin tinggi pula harapan pelanggan terhadap atribut mutu dimaksud sehingga harus dijadikan prioritas dibanding atribut mutu lainnya.

7) Tahap prioritas persyaratan teknis dilakukan untuk memperoleh urutan ketentuan teknis yang perlu mendapat perhatian dan prioritas untuk diperbaiki atau dikembangkan dalam rangka memenuhi persyaratan pelanggan. Nilai prioritas ditetapkan secara relatif 
dengan mempertimbangkan nilai prioritas harapan pelanggan dan nilai matrik hubungan antara persyaratan teknis dengan persyaratan pelanggan.

\section{Teknik Fuzzy AHP}

Tahapan fuzzy AHPyang digunakan dalam penelitian ini menurut Ayag dan Ozdemir (2006), dan Kwong dan Bai (2002)adalah sebagai berikut:

1) Melakukan fuzzifikasi, proses untuk mengubah skala numerik menjadi nilai fuzzy, skala Saaty (1 - 9) dan menetapkan fungsi keanggotaannya (membership function) menggunakan model TFN (triangular fuzzy number). Fuzzifikasi adalah proses untuk mengubah skala numerik menjadi nilai fuzzy (Gambar 2). Artinya, nilai 1 (sama penting) mempunyai range fungsi keanggotaan $1-3$ (sedikit lebih penting) dengan derajat keanggotaan $(\mu) 0-1$, sedangkan nilai 3 mempunyai rangefungsi keanggotaan $1-5$ (jelas lebih penting) dan seterusnya.

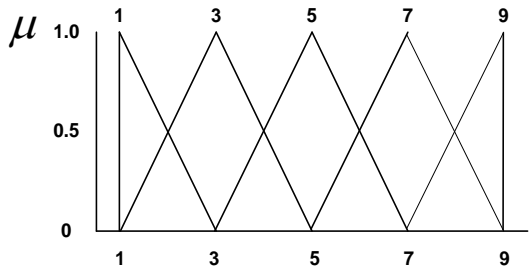

Gambar 2. Fungsi keanggotaan dengan model TFN

2) Melakukan penilaian perbandingan berpasangan antar elemen pada jenjang hierarki yang sama menggunakan himpunan fuzzy hingga diperoleh matrik perbandingan fuzzy. Matrik yang diperoleh dikonversi menjadi matrik perbandingan yang mempunyai batas atas dan batas bawah dari bilangan fuzzy dengan menggunakan persamaanpersamaan di bawah ini.

$$
\begin{array}{ll}
\mathbf{1} \sim=[1,3-2 \alpha] & \\
\mathbf{3} \sim=[1+2 \alpha, 5-2 \alpha] & 3 \sim^{-1}=\left[\frac{1}{5-2 \alpha}, \frac{1}{1+2 \alpha}\right] \\
\mathbf{5} \sim=[3+2 \alpha, 7-2 \alpha] & 5 \sim^{-1}=\left[\frac{1}{7-2 \alpha}, \frac{1}{3+2 \alpha}\right] \\
7 \sim=[5+2 \alpha, 9-2 \alpha] & 7 \sim^{-1}=\left[\frac{1}{9-2 \alpha}, \frac{1}{5+2 \alpha}\right] \\
\mathbf{9}=[7+2 \alpha, 9-2 \alpha] & 9 \sim^{-1}=\left[\frac{1}{9-2 \alpha}, \frac{1}{7+2 \alpha}\right]
\end{array}
$$

3) Melakukan konversi matrik perbandingan fuzzysebelumnya menjadi matrik perbandingan yang mempunyai nilai crips menggunakan persamaan berikut ini.Nilai nilai kepercayaan dari pakar $(\alpha)$ dan indeks optimistik $(\mu)$ yang digunakan adalah 0.5.

Simbol $\tilde{a}^{\alpha}{ }_{i j}$ adalah nilai perbandingan berpasangan untuk faktor ke-i dengan faktor kej. Simbol a ${ }^{\alpha}{ }_{\mathrm{iju}}$ menunjukkan nilai batas atas fuzzy untuk faktor ke-i dengan faktor ke-j, sedangkan $\mathrm{a}^{\alpha}{ }_{\mathrm{ijl}}$ adalah nilai batas bawahnya.

$\tilde{a}^{\alpha}{ }_{\mathrm{ij}}=\mu \mathrm{a}_{\mathrm{iju}}^{\alpha_{\mathrm{ij}}}+(1-\mu) \mathrm{a}_{\mathrm{ijl}}^{\alpha_{1},} \quad \forall \mu \in[0,1]$

4) Melakukan agregasi nilai hasil perbandingan berpasangan dari tiga orang narasumber menggunakan teknik rata-rata geometrik (Marimin, 2004).

5) Menghitung nilai eigen vektor $(\lambda)$ dan $\lambda$ max dengan operasi matrik. Nilai eigen selanjutnya digunakan sebagai prioritas atau bobot, baik prioritas lokal maupun global, untuk menilai prioritas alternatif-alternatif yang dibandingkan. 
6) Menentukan Consistency Ratio (CR) untuk menilai secara langsung konsistensi perbandingan berpasangan. Apabila $\mathrm{CR} \leq 0.1$, maka perbandingan telah dilakukan secara konsisten.

\section{HASIL DAN PEMBAHASAN}

Analisis dengan menggunakan metode QFD menghasilkan matrik perencanaan disain mutu produk dan proses yang dituangkan dalam matrik HoQ (Gambar 3). Hasil identifikasi terhadap suara pelanggan diperoleh bahwa terdapat 18 atribut mutu kecap asin yang diharapkan/dipersyaratkan oleh pelanggan yang menurut Garvin (Jakpar et al, 2012)terbagi ke dalam 8 dimensi. Berdasarkan hasil analisis menggunakan fuzzy pairwise comparison, atribut mutu kemasan tidak mudah pecah/rusak pada dimensi reliabilitymempunyai bobot kepentingan tertinggi dari perspektif pelanggan dengan nilai $20.73 \%$, berikutnya adalah warna coklat terang dan rasa asin tapi tidak terlalu tajam dari dimensi performancedengan nilai bobotmasing-masing $15.51 \%$ dan $13.14 \%$.

Hasil benchmarking dengan produk kecap asin merk ABCmenunjukkan bahwa kecap asin cap Ikan Suramas mempunyai keunggulan dari segi warna kecap (performance) dan adanya kemasan isi ulang (feature). Warna kecap asin cap Ikan Suramas sedikit lebih terang sehingga sesuai untuk hampir semua masakan. Pelanggan kecap asin Suramas sangat menyukai kemudahan yang diberikan perusahaan kecap asin cap Ikan Suramas yang mengurangi harga produknya dengan nilai yang setara dengan harga kemasan botol kecap sehingga dengan sistem ini harga kecap asin cap Ikan Suramas menjadi lebih murah. Sementara, atribut mutu yang menjadi kelemahannyaterletakpada dimensi serviceability(ketersediaan produk; promosi gencar), aesthethics (label, warna dan bentuk kemasan yang menarik), durability (umur simpan produk; rasa dan aroma yang tidak mudah berubah; tidak adanya endapan selama penyimpanan). Atribut mutu yang menjadi kelemahan memiliki nilai skala kenaikan antara 1.25 - 1.5 yang menunjukkan bahwa pencapaianatribut tersebut masih di bawah target perusahaan sehingga perlu untuk diperbaiki.

Atribut mutu kecap asin yang menjadi prioritas bagi perusahaan kecap asin Suramas untuk dipenuhi agar dapat memuaskan pelanggan dan meningkatkan kinerja mutu perusahaan direpresentasikan dengan nilai prioritas pelanggan. Tiga atribut mutu yang mempunyai prioritas tertinggi berturut-turut adalah warna, rasa dan aroma, rasa asin tapi tidak terlalu tajam,ketersediaan produk dan label komposisi dan kehalalan produk. 


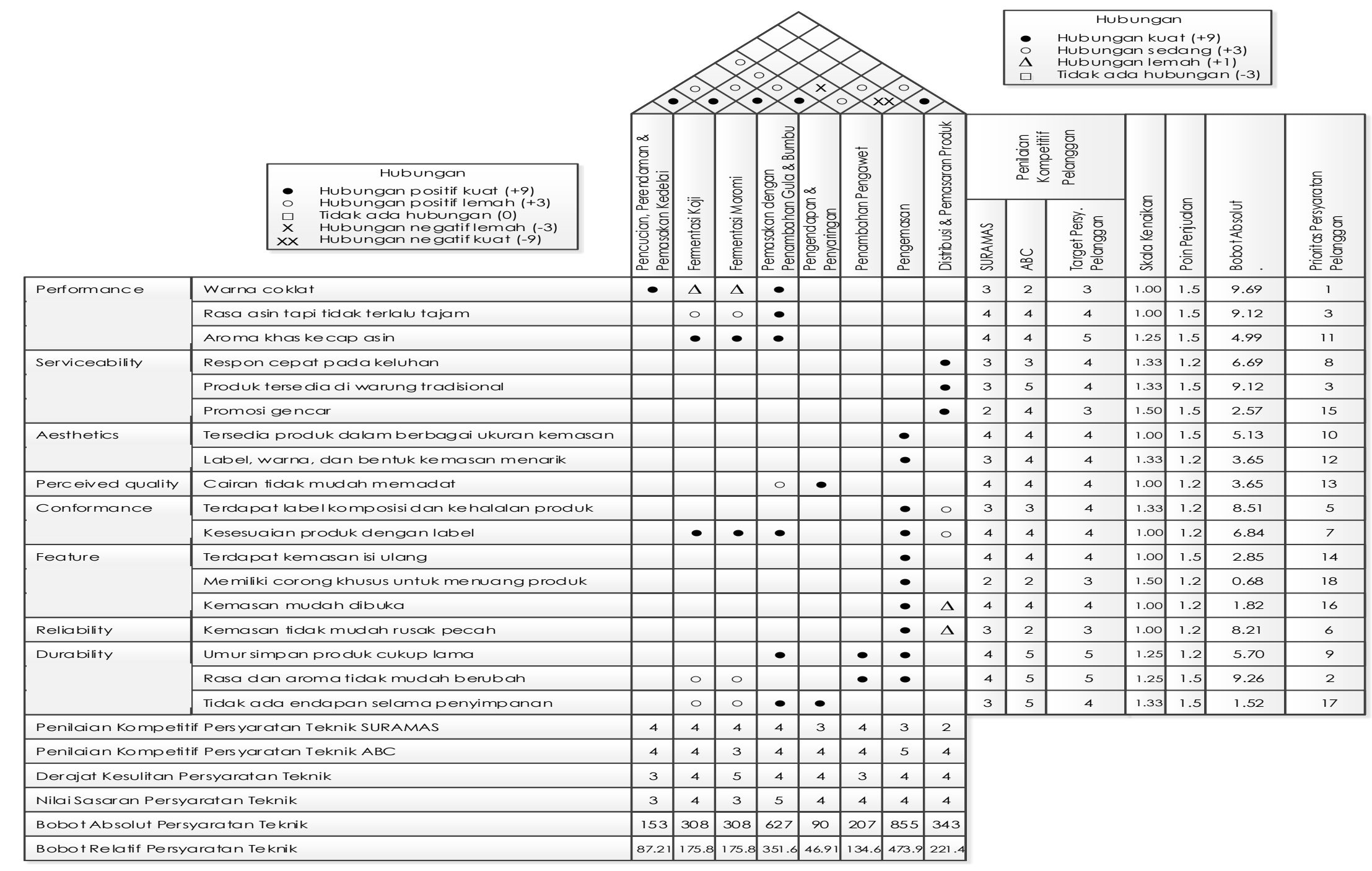

Gambar 3. Matrik House of Quality (HoQ) kecap asin cap Ikan Suramas 
Dalam rangka mencapai kinerja mutu yang dapat memuaskan harapan pelanggan, terdapat delapan persyaratan teknis yang perlu diperhatikan oleh perusahaan mulai dari proses persiapan bahan baku (pencucian, perendaman dan pemasakan kedelai) hingga proses distribusi dan pemasaran produk. Tiga persyaratan teknis yang mempunyainilai prioritas tertinggi adalah proses pengemasan (473.9), pemasakan denganpenambahan gula dan bumbu (351.6), dan distribusi dan pemasaran produk (221.4). Pengemasan mempunyai keterkaitan kuat dengan 10 atribut mutu kecap asinyang terdapat pada dimensi aesthetics, conformance, feature, reliability, dan durability. Atribut mutu yang terkait diantaranya adalah desain label, bentuk, ragam dan ketahanan kemasan, daya tahan produk serta kestabilan rasa dan aroma kecap asin.Keterkaitan antara persyaratan teknis lainnya dengan persyaratan mutu pelanggan dapat ditelusuri pada matrik HoQ. Apabila persyaratan teknis dengan prioritas tinggi mampu ditingkatkan kinerjanya secara terus-menerus, maka sebagian besar persyaratan pelanggan akan meningkat mutunya sehingga kepuasan pelanggan dapat dipenuhi.

Matrik HoQ memberikan informasi yang sangat berharga yang dapat dijadikan landasan kuat dalam perbaikan mutu yang berbasis pelanggan (customer driven) dari kecap asin Suramas secara efektif dan efisien. Analisis lanjut yang dapat dilakukan berdasarkan informasi tersebut adalah mengidentifikasi atribut mutu yang mempunyai nilai tinggi pada prioritas harapan pelanggandan berstatus harus "diperbaiki", yaitu atribut yang harus diupayakan untuk ditingkatkan kinerjanya sehingga mampu memuaskan pelanggan.Status tersebut diperoleh setelah mempertimbangkan nilai benchmarking dan faktor skala kenaikan. Status "diperbaiki" diberikan apabila nilai skala kenaikan lebih dari satu dan nilai benchmarking pada atribut mutu tersebut lebih rendah dari produk pesaing. Atau, jika nilai benchmarkingsama, namun nilai skala kenaikannya lebih dari satu dan atribut tersebut mempunyai nilai persyaratan pelanggan yang tinggi, maka diberikan status "diperbaiki".

Perbaikan atribut mutu dengan status "diperbaiki", dilakukan dengan cara memperbaiki persyaratan teknis yang mempunyai keterkaitan erat dengan atribut mutu yang dimaksud. Gambar 4 merupakan hasilpenelusuran dari matrik HoQ hingga diperoleh hubungan antar atribut mutu dengan status "diperbaiki" dengan persyaratan teknis dari prioritas tertinggi hingga terendah.

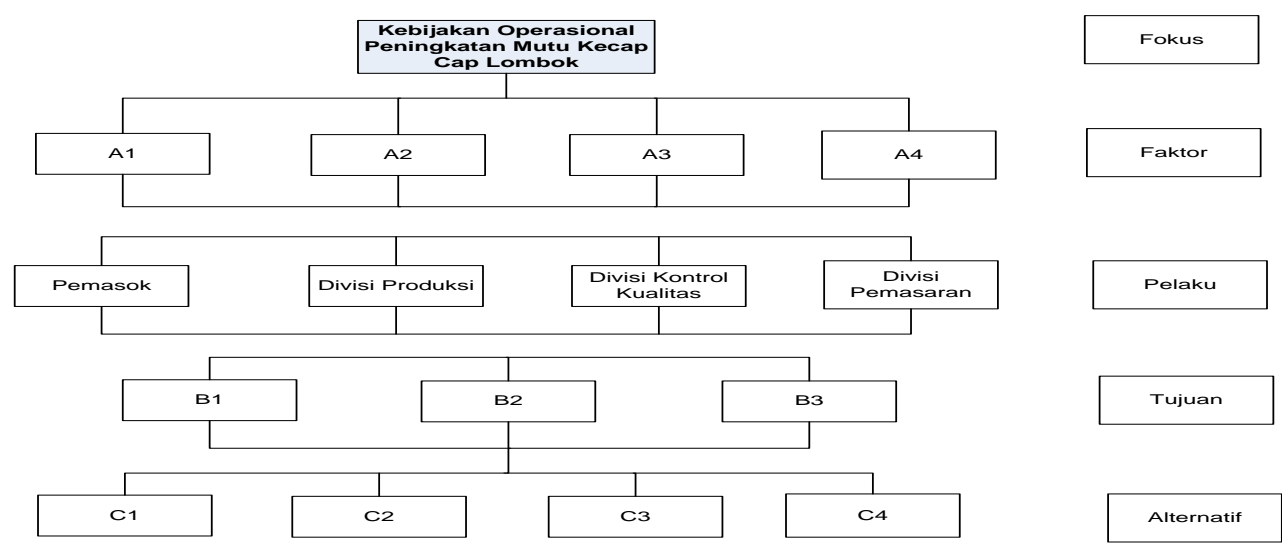

Gambar 4. Keterkaitan atribut mutu dengan status "diperbaiki” dengan persyaratan teknis

Ketujuh persyaratan teknis tersebut selanjutnya dijabarkan untuk mengetahui faktor-faktor utama yang mempunyai pengaruh terhadap tujuh atribut mutu yang "diperbaiki". Identifikasi faktor utama dapat dilakukan dengan bantuan diagram sebab tulang ikan (fishbone) (Gambar 5). Faktor utama diklasifikasikan ke dalam lima katagori, yaitu material, peralatan, proses, manusia dan pasar. Perbaikan pada persyaratan teknis dilakukan dengan berlandaskan terhadap kelima faktor tersebut. 
Misalnya, untuk memperbaiki agar atribut rasa dan aroma tidak mudah berubah, persyaratan teknis yang harus diperbaiki adalah proses pengemasan, fermentasi dan penambahan bahan pengawet. Perbaikan pada proses pengemasan dapat dilakukan dengan cara mengidentifikasi komponen pada empat faktor utama, yaitu material, peralatan, proses, dan manusia. Yang perlu diidentifikasi pada faktor material adalah bahan pengemas yang digunakan selama ini apakah jenis dan ketebalannya telah sesuai. Pada faktor peralatan, perhatian perlu difokuskan pada alat pengemas yang digunakan apakah berpengaruh terhadap higienitas produk dan kemampuan untuk melakukan exhausting pada produk yang akan dikemas. Pada faktor manusia, yang perlu diperhatikan adalah apakah sistem kerja dan pengawasan yang dilakukan selama ini telah sesuai atau belum hingga mempunyai akibat terhadap kestabilan rasa dan aroma.

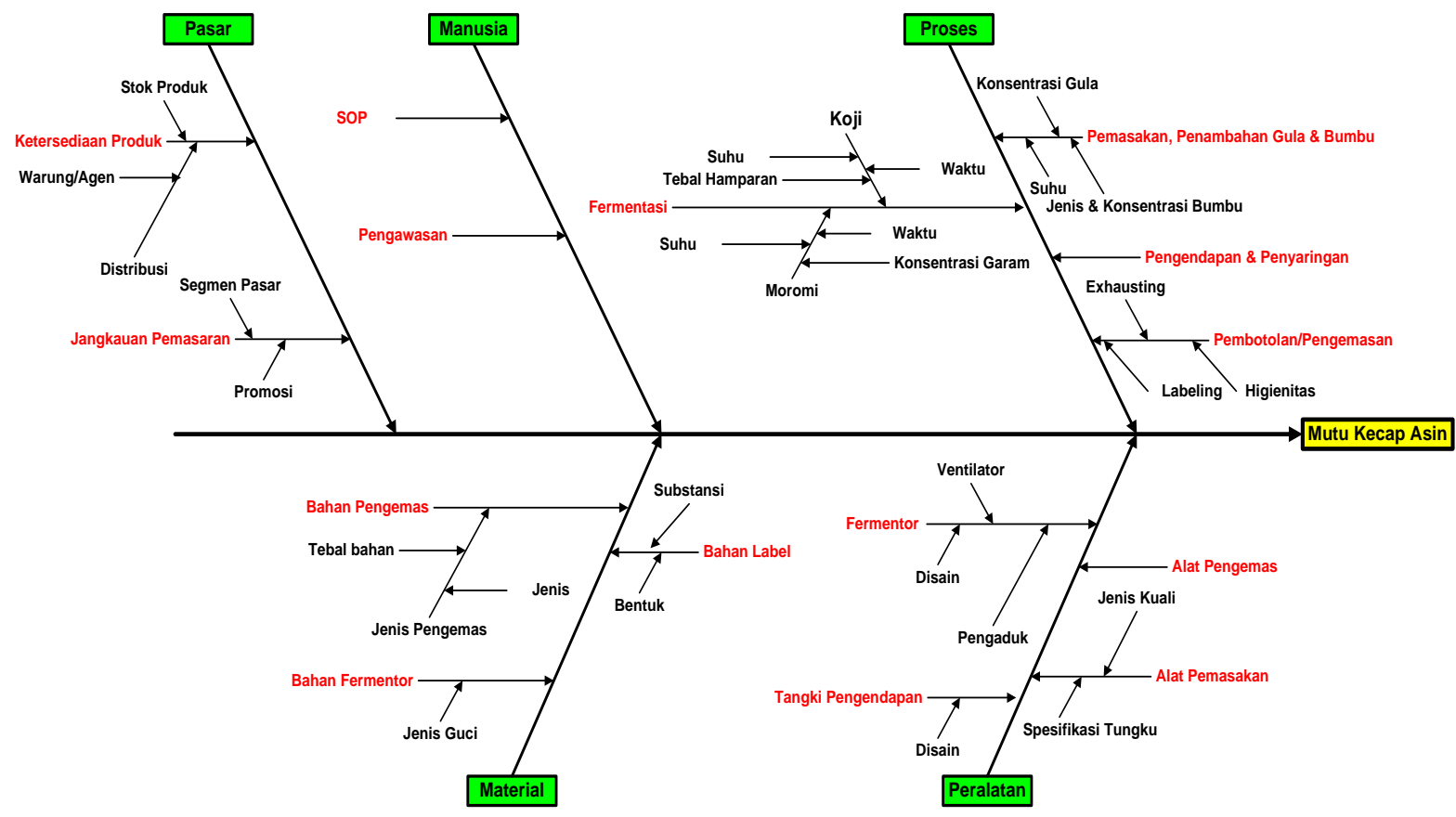

Gambar 5. Diagram fishbone peningkatan mutu kecap asin Cap Ikan Suramas

Untuk meningkatkan tingkat kepuasan pelanggan dan menjadi perusahaan kecap asin yang berdaya saing tinggi, perusahaan kecap asin cap Ikan Suramas dituntut untuk mampu memperbaiki enam persyaratan teknis yang terpilih dalam rangka meningkatkan kinerja atribut-atribut mutu yang kurang memuaskan atau harus "diperbaiki". Hal tersebut mampu diwujudkan, apabila perusahaan mempunyai strategi efektif, yaitu strategi yang implementasinya selalu didasarkan atas pencapaian tujuan dengan mempertimbangkan kompleksitas permasalahan yang ada, bersifat integratif dan sesuai dengan kemampuan sumber daya perusahaan.

Untuk menghasilkan strategi efektif digunakan teknik fuzzy AHP. Struktur hierarki peningkatan mutu produk kecap asin Cap Ikan Suramas(Gambar 6) terdiri dari lima jenjang, yaitu fokus, faktor, pelaku, tujuan, dan alternatif strategi. Fokus adalah hal yang menjadi tujuan utama, yaitu strategi peningkatan mutu kecap asin cap Ikan Suramas. Faktor adalah hal-hal yang berpengaruh terhadap mutu kecap asincap Ikan Suramas, yaitu teknologi proses produksi, pasar, bahan dan peralatan, dan kemampuan manajemen. Faktor-faktor tersebut merupakan hasil sintesis diagram fishbone. Pelaku adalah pihakpihak yang akan menjadi pelaksana maupun kontributor penting bagi upaya peningkatan mutu kecap asin. Tujuan adalah hal yang ingin dicapai dalam penyusunan strategi, yaitu 
peningkatan jangkauan pemasaran, peningkatan produktivitas dan kapabilitas proses, dan peningkatan kepuasan pelanggan. Alternatif strategi adalah hal-hal yang dilakukan untuk mencapai tujuan yang diinginkan, yaitu penerapan GMP/HACCP, penerapan Gugus Kendali Mutu (GKM), dan diferensiasi mutu produk.

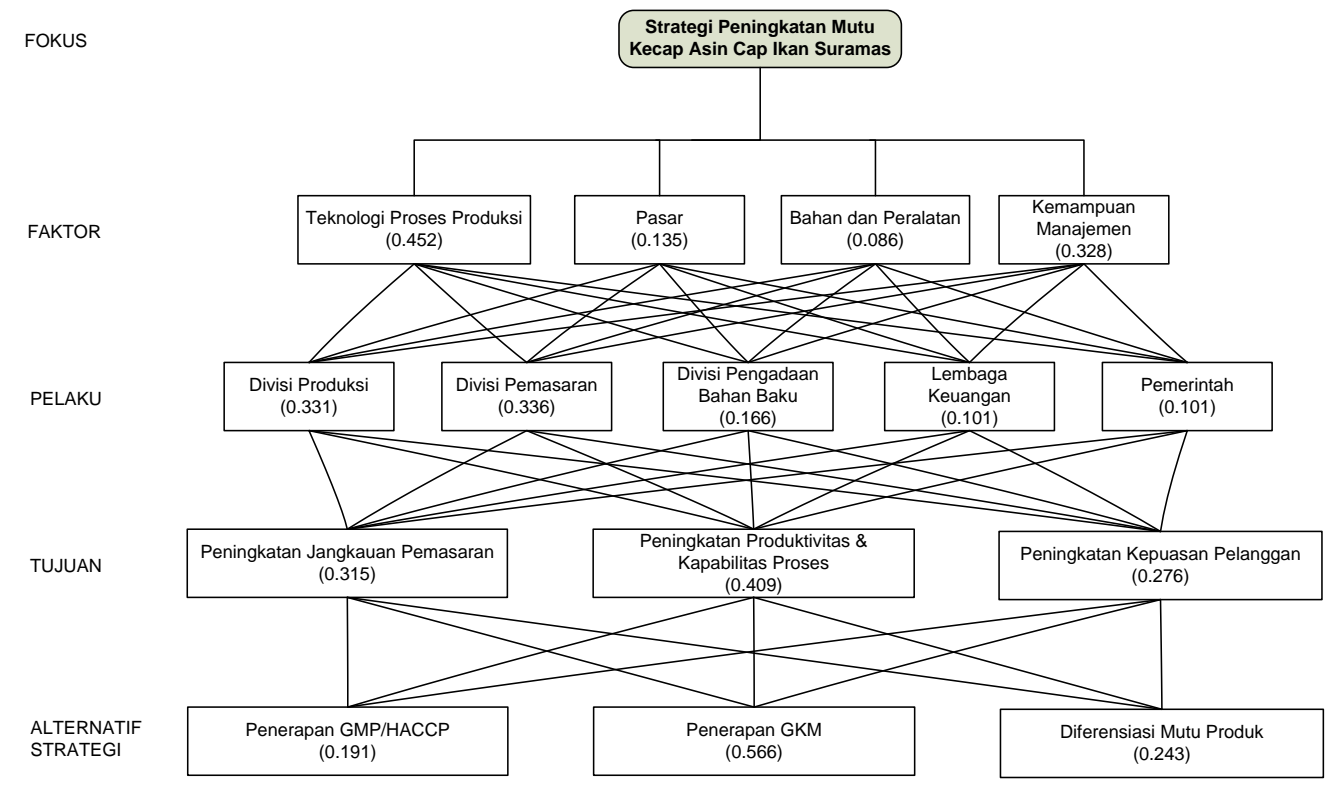

Gambar 6. Hierarki strategi peningkatan mutu kecap asin Cap Ikan Suramas

Alternatif strategi yang mempunyai bobot terbesar untuk meningkatkan mutu kecap asin Cap Ikan Suramas adalah GKM (56.6\%). Penerapan GKM diyakini lebih efektif karena dapatmendayagunakan seluruh sumberdaya yang dimiliki perusahaan terutama SDM secara lebih baik. Cara kerja GKM sangat teroganisir, sistematis dan terukur sehingga dapat menyelesaikan permasalahan kompleks(Okoet al, 2013).

Tim GKM yang dibentuk oleh perusahaan, dengan fasilitator dinas perindustrian, akademisi perguruan tinggi, maupun praktisi industri kecap lainnya dapat diarahkan untuk memperbaiki persyaratan-persyaratan teknis yang menjadi sebab terjadinya peningkatan kepuasan kepada persyaratan pelanggan. Tim dapat bekerja secara bertahap dimulai dengan memperbaiki persyaratan teknis yang berhubungan langsung dengan atribut mutu dengan prioritas tertinggi untuk diperbaiki, bergerak ke prioritas yang lebih rendah sedemikian rupa sehingga seluruh permasalahan yang terjadi dapat ditangani dengan efektif. Dengan demikian, pembentukan GKM menjadi strategi yang sangat tepat bagi perusahaan kecap asin ini dalam rangka peningkatan mutu produk secara efektif dan berkesinambungan.

Adanya strategi ini memberikan implikasi luas bagi perusahaan dan pemerintah. Perusahaan kecap Cap Ikan Suramas perlu mempersiapkan SDM dan SOP/SSOP secara lebih baik agar dapat melaksanakan GKM secara efektif. Terpilihnya strategi GKM menjadi titik tolak (entry point) bagi pemerintah daerah untuk merevitalisasi kembali program pembinaan GKM bagi IKM. Pemerintah daerah melalui dinas terkait mempunyai tanggung jawab untuk mengadakan pelatihan, pemasyarakatan, penerapan, dan pengembangan GKM melalui pembentukna klinik GKM sebagaimana diamanatkan oleh kebijakanMenteri Perindustrian dan Perdagangan melalui SK No. 243/M/SK/11/1995 tentang pendirian klinik GKM-IKM.

\section{KESIMPULAN}


Penggunaan metode QFD dan AHP dengan menerapkan logika fuzzy telah dapat menghasilkan strategi yang efektif dalam upaya meningkatkan mutu kecap asin Cap Ikan Suramas. Efektifitas strategi tersebut dinilai berdasarkan karakteristiknya yang mampu mengarahkan perbaikan kinerja mutu bagi persyaratan pelanggan yang menjadi prioritas untuk ditingkatkan kinerjanya melalui perbaikan persyaratan-persyaratan teknis yang mempunyai keterkaitan langsung dengan atribut mutu yang dimaksud.

Mutu kecap asin yang menjadi harapan pelanggan terdiri dari 18 atribut, terbagi ke dalam 8 dimensi mutu. Tidak semua atribut mutu tersebut mampu dipenuhi oleh kecap asin Cap Ikan Suramas. Hanya 7 atribut yang mampu dipenuhi, yaitu 1) warna coklat terang; 2) rasa asin tapi tidak terlalu tajam; 3) ketersediaan produk dalam berbagai ukuran kemasan; 4) daya alir cairan yang tidak mudah memadat; 5) kesesuaian produk dengan label; 6) kemasan tidak mudah pecah/rusak; dan 7) kemasan mudah dibuka.

Kecap asin Cap Ikan Suramas unggul dibandingkan pesaingnya dari segi warna kecap dan adanya kemasan isi ulang, sedangkan yang menjadi kelemahannya adalah ketersediaan produk, promosi, disain label, bentuk kemasan, umur simpan, dan kestabilan rasa dan aroma.

Persyaratan teknis yang menjadi prioritas untuk diperbaiki dalam rangka meningkatkan kinerja atribut mutu yang mampu memuaskan harapan pelanggan adalah 1) proses pengemasan; 2) proses distribusi dan pemasaran produk; 3) proses fermentasi; 4) proses penambahan bahan pengawet; 5) proses pemasakan dengan penambahan gula dan bumbu; dan 6) proses pengendapan dan penyaringan.

Strategi efektif peningkatan mutu kecap asin bagi perusahaan adalah membentuk GKM karena strategi ini mampumendayagunakan seluruh sumberdaya yang dimiliki perusahaan terutama SDM secara lebih baik untuk mencapai tujuan. Melalui GKM,atribut mutu yang dapat ditingkatkan kinerjanya tidak hanya yang tercakup ke dalam proses produksinya saja, melainkan atribut mutu yang terkait dengan proses distribusi dan pemasaran produk.

\section{DAFTAR PUSTAKA}

Ali J, Kapoor S, and Moorthy J. 2010. Buying Behaviour of Consumers for Food Products in An Emerging Economy. British Food Journal. Vol. 112 (2): 109-124. DOI 10.1108/00070701011018806.

Ayag Z, and Ozdemir RG. 2006. A Fuzzy AHP Approach to Evaluating Machine Tool Alternatives. J of Intelligent. Vol. 17:179 - 190.

Chan LK, and Wu ML. 2002. Quality Function Deployment: A Literature Review. European Journal of Operational Research. Vol. 143: 463-497.

Gharakhani D and Eslami J. 2012. Determining Customer Needs Priorities for Improving Service Quality Using QFD. International Journal of Economics and Management Sciences. Vol. 1 (6): 21 - 28.

Hamidullah, Akbar R, Noor S, Shah W, and Inayatullah. 2010. QFDas A Tool for Improvement of Car Dashboard. Journal of Quality and Technology Management. Vol. VI (1): $1-22$.

Ishizaka A,and Labib A. 2011. Review of the Main Developments in the Analytic Hierarchy Process. Expert Systems with Applications. Vol. 38(11): 14336-14345.

Jakpar S, Sze Na, Johari A, Mynt KT. 2012. Examining the Product Quality Attributes That Influences Customer Satisfaction Most When the Price Was Discounted: A 
Case Study in Kuching Sarawak. International Journal of Business and Social Science. Vol. 3 (23): $221-236$.

Jaiswal ES. 2012. A Case Study on Quality Function Deployment (QFD). IOSR Journal of Mechanical and Civil Engineering (IOSR - JMCE). Volume 3 (6): 27 - 35.

Josling T. 1999.Globalization of the Food Industry and its Impact on Agricultural Trade Policy [Paper]. The Conference on Agricultural Globalization, Trade and the Environment. March 7-9. Berkeley: University of California.

Kwong and Bai. 2002. A Fuzzy AHP Approach to Determination of Importance Weights of Customer Requirements in Quality Function Deployemen. J. of Intelligent Manufacturing. Vol. 5 (13).

Law HW, and Hua M. 2007. Using Quality Function Deployment in Singulation Process Analysis. Engineering Letters. Vol. 14 (1). Advance online publication: 12 February 2007.

Lemeshow S, and David WH. 1997. Besar Sampel dalam Penelitian Kesehatan (terjemahan). Yogyakarta: Gadjahmada University Press.

Magutu PO. 2010. Business Process Reengineering for Competitive Advantage. African Journal of Business \& Management (AJBUMA). Vol. 1. 16 Pages.

Marimin. 2005. Teori dan Aplikasi Sistem Pakar dalam Teknologi Manajerial. Bogor: IPB Press.

Marimin dan Muspitawati H. 2002. Kajian Strategi Peningkatan Kualitas Produk Industri Sayuran Segar (Studi Kasus di Sebuah Agroindustri Sayuran Segar). Jurnal Teknol. Dan Industri Pangan. Vol. XIII (3).

Passemard D, and Kleiner BH. 2000. Competitive Advantage in Global Industries. Management Research News. Vol. 23 (7/8). ABI/INFORM Global.

Tseng CC, and Torng CC. 2011. Prioritization Determination of Project Tasks in QFD Process Using Design Structure Matrix. Journal of Quality. Vol. 18 (2 ): 137 153. 